\title{
Steady-State Modeling of Heat Transfer on the Recovery System of Condensing Boiler
}

\author{
Joachim Ntonda ${ }^{*}$, Frederic Lontsi ${ }^{1}$, Francois Njock Bayock ${ }^{2}$ \\ ${ }^{1}$ Laboratry of Energy, Materials, Modelisation and Method, University of Douala, Douala, Cameroon \\ ${ }^{2}$ Department of Mechanical Engineering, ENSET Douala, University of Douala, Douala, Cameroon \\ Email: *Joachim_ntonda@yahoo.com
}

How to cite this paper: Ntonda, J., Lontsi, F. and Bayock F.N. (2021) Steady-State Modeling of Heat Transfer on the Recovery System of Condensing Boiler. Journal of Power and Energy Engineering, 9, 29-40. https://doi.org/10.4236/jpee.2021.97003

Received: June 3, 2021

Accepted: July 17, 2021

Published: July 20, 2021

Copyright () 2021 by author(s) and Scientific Research Publishing Inc. This work is licensed under the Creative Commons Attribution International License (CC BY 4.0).

http://creativecommons.org/licenses/by/4.0/

(c) (i) Open Access

\begin{abstract}
The increase of energy production is very important nowadays. It is necessary to improve the performance and efficiency of heat production facilities. The objective is to reduce pollutant emissions and regulate investment costs. One of the solutions is to control fuel and electricity consumption. This article develops a new model of simulation heat diffusion on the recovery system of condensing boiler. The method is based on the first and second thermodynamic systems. The Numerical discrete Model (NDM) was applied using MATLAB to simulate different characteristics of heat transfer in the recovery system. The result shows that the recovery unit can absorb the following temperatures; the range from $88^{\circ} \mathrm{C}$ to $90.7^{\circ} \mathrm{C}$ when the length of the tube is between respectively 110 and $111 \mathrm{~m}$. the energy efficiency was between 0.55 and 0.57 which allowed confirming the model. This new model has some advantages such as; the use of an instantaneous calculation time. The heat recovered by the water tank can also serve as preheating different systems. One part of the heat recovered will be accumulated to be used as domestic hot water.
\end{abstract}

\section{Keywords}

Heat Recovery, Steady-State, Numerical Discrete Model

\section{Introduction}

The major problem nowadays is the control of energy and fuel consumption in different industrial companies. Increase productivity by reducing energy consumption. The most direct and effective solution is to optimize energy systems and transform energy-saving technologies in industries and make full use of waste heat in the energy consumption equipment of industrial companies. To 
solve the issue of waste heat in the energy-consuming is to offer a rudimentary and economic recovery system of waste heat in the industries productions. Robert Mbiake et al. [1] show that today boilers lose about 30\% of waste heat, but the overall recovery rate of this heat is low or non-existent. The environmental issues caused by the combustion of fossil fuels are increasingly important and sometimes more serious, it is very important to recycle waste heat completely and rationally. Many researchers are studied different ways to recycle waste heat. A simulation of a half-effect absorption system was developed by Arivazhagan et al. [2]. The system was applied to cold storage with the R-134a-DMAC couple. The modeling of such a system makes it possible to define the performance of the system and the results were compared with those of the ammonia-water couple. The modeling is carried out in a steady state with neglected load losses and exchanger efficiencies set at 0.7 . The mass balance and energy balance equations were listed for each component with expressions of the rate of circulation under different pressure. The performance efficiency (COP) value between 0.35 and 0.46 is obtained for an evaporation temperature between $-5^{\circ} \mathrm{C}$ and $5^{\circ} \mathrm{C}$, a hot spring temperature of $70^{\circ} \mathrm{C}$, and that of condensation between $20^{\circ} \mathrm{C}$ and $30^{\circ} \mathrm{C}$. Chenghu Zhang et al. [3] characterized a new total heat recovery system using CaCL2 as a working fluid after thermal modeling and good physical analysis, they obtained very good results. Haoran Zhen, Wenliang Feng et al. [4] carried out practical tests through existing flue gas heat recovery systems. Existing projects to transform waste heat recovery engineering from flue gases, and analyzed the economic and energy-saving performance of heat recovery and the economic performance of heat storage technology in the recovery of waste heat from flue gases. The recovery of waste heat from flue gases throughout the heating season is carried out using heat storage technology. And the season running time of the waste heat recovery unit is extended. The efficiency of gas use from the heat source is improved Pashchenko Dmitry [5] used methanol, ethanol, and other biofuels for the thermochemical recovery of industrial waste heat. Using the ethanol steam reforming heat recovery system, they proposed a design scheme for a thermochemical fuel recovery system, diagram of thermochemical fuel oil consumption equipment. Through calculations and analysis, good results have been obtained in the recovery of residual heat Hongzhi Zhang et al. The major issues were the realization that requires huge financial means. Hongzhi Zhang et al. [6] have set up a three-dimensional dynamic simulation platform, which provides a better solution for the recovery of residual heat.

Yue Lifang et al. [7] proposed a recovery device to collect heat lost from gas combustion that used cold water in the heat collection hood as a means of absorbing excess heat emitted during gas combustion, and the hot water generated enters the storage tank to be stored and reused. This device makes it possible not only to use energy efficiently but also to improve the efficiency of gas use. However, this device posed a problem of space requirement. Amaris et al. [8] worked on the experimental thermal performance and modeling of a waste heat recovery unit in an energy cogeneration system, their experimental tests show that the 
recovery unit recovers from $18.8 \mathrm{~kW}$ to $8.1 \mathrm{~kW}$ when the output power of the microturbine varies from $23 \mathrm{kWe}$ to $4 \mathrm{kWe}$. The results also show that the overall heat transfer coefficient varies between $243 \mathrm{~W} \cdot \mathrm{m}^{-2} \cdot \mathrm{K}^{-1}$ and $89 \mathrm{~W} \cdot \mathrm{m}^{-2} \cdot \mathrm{K}^{-1}$. On the other hand, the system might have higher electricity or gas cost.

Fu Li et al. [9] have developed a technology for recovering heat lost by condensing flue gases combining an absorption heat pump and a gas boiler, which has solved the problem of the temperature of the return water too high to recover the condensing heat of the flue gases. This technology can increase efficiency by more than $5 \%$, compared to existing technology for recovering condensing heat from boiler flue gases. Ye Bicui et al. [10] analyzed the performance of the system by modeling. Concerning the energy-intensive drying process, they have proposed a two-stage open absorption heat pump system intending to recover latent heat from the exhaust gases and generate the necessary steam, which is a good way to improve the energy efficiency of the system.

Wang Fang et al. [11], proposed a technology for the deep recovery of waste heat from boiler flue gases, based on absorption heat pump equipment. However, due to the use of water as a medium, recovery of the system is limited. For medium and low-temperature heating, with return water as a means of colling to recover waste heat, the heat recovery system is limited. From cooling to recover waste heat, the inlet temperature is lower, and the efficiency of recovery is not high. The absorption heat pump has unique advantages in terms of low-quality waste heat recovery and quality improvement, but the failure rate is very low. Taddaeusjuliuset al. [12] evaluated the performance of a heat recovery unit of passenger vehicles they found very interesting results especially the thermal efficiency which was evaluated at $4.93 \%$. Their analysis was only concentrated on the passenger vehicle. They did not work on industrial equipment like trucks and industrial facilities. The research developed in this work is based on a numerical discrete model (NDM) using MATLAB to simulate a thermal diffusion condensing Boiler The range of heat recovery will be evaluated to estimate the acceptable range of energy efficiency.

\section{Numerical Modelling}

\subsection{Physical Modelling of the System}

Figure 1 shows the heat recovery diagram which has many parts. It can be seen in the heat recovery diagram; a boiler, a feed tank, and a storage tank: a 4-ton boiler has a flow rate of $4000 \mathrm{Kg} / \mathrm{h}$ of steam and operates with a control pressure of $7 \mathrm{bar}$, the temperature of the chimney smoke is between $150^{\circ} \mathrm{C}$ and $177.7^{\circ} \mathrm{C}$ the feed sheet has a daily capacity of $35 \mathrm{~m}^{3}$ at the supply water temperature of $20^{\circ} \mathrm{C}$. This water will get in the recovery system and will intersect the heat by conduction and comes out at a temperature of about $90^{\circ} \mathrm{C}$. Some of this water returns to the feed sheet to serve as preheating and another part is stored in a storage tank and will be used as domestic hot water. The heat recovery system is a stainless steel tube wrapped around the chimney having a length to determine 


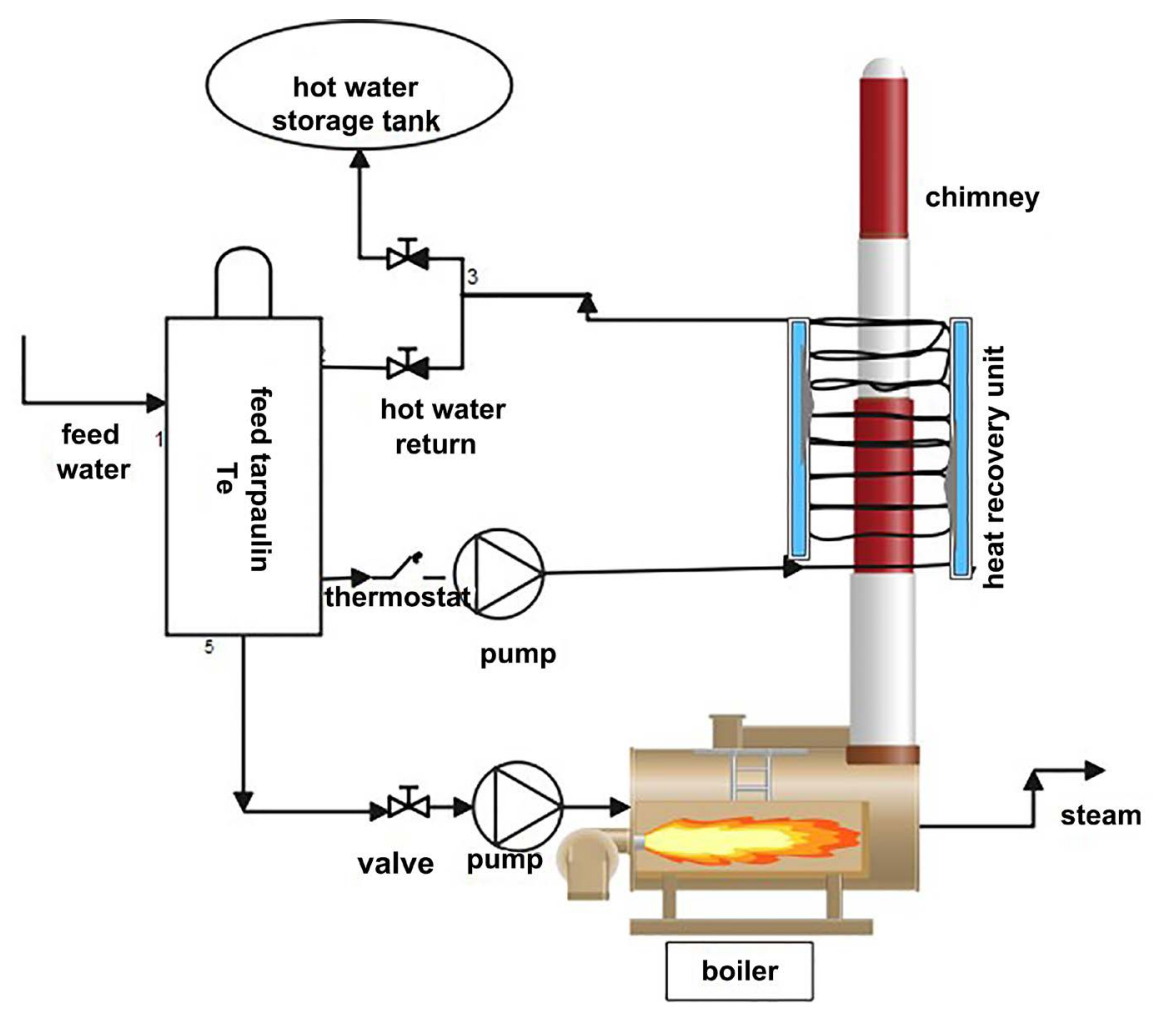

Figure 1. Heat recovery system diagram.

the outer/inner diameter of the tube, $152 / 165 \mathrm{~mm}$, and is insulated with the help of heat insulation. A pump whose characteristics are defined using the abacus is chosen so that its volume flow rate is $20 \mathrm{~m}^{3} / \mathrm{h}$; a control thermostat is installed just at the inlet of the pump which will ensure the maintenance of the temperature at $90^{\circ} \mathrm{C}$ at the outlet of the recovery system.

\subsection{Physical Model of the Prototype}

Figure 2 shows the physical model of the recovery system studied: The recovery system is composed of a chimney and a stainless steel tube. The smoke gets in the chimney at the temperature of $T_{f e}=150^{\circ} \mathrm{C}$ and comes out at the temperature $T_{f s}$ lower than that at the entrance. However the water enters the coil with a temperature $T_{e}$ and circulates along with the coil by recovering the heat ceded by the fumes this water will come out with a temperature $T_{s}$ higher, the whole constitutes the module of the recovery system.

Where $a$ is the chimney inside the hot fumes circulate, $b$ is the tube in which the water circulates. $T_{f e}$ represents the inlet fumes temperature and $T_{f s}$ is the outlet fumes temperature. $T_{e}$ and $T_{s}$ represent respectively the inlet and outlet water temperatures.

\subsection{Modelling Assumptions}

The following assumptions are accepted to simplify our model.

- Heat transfer is unidirectional and the surface is at a uniform temperature. 


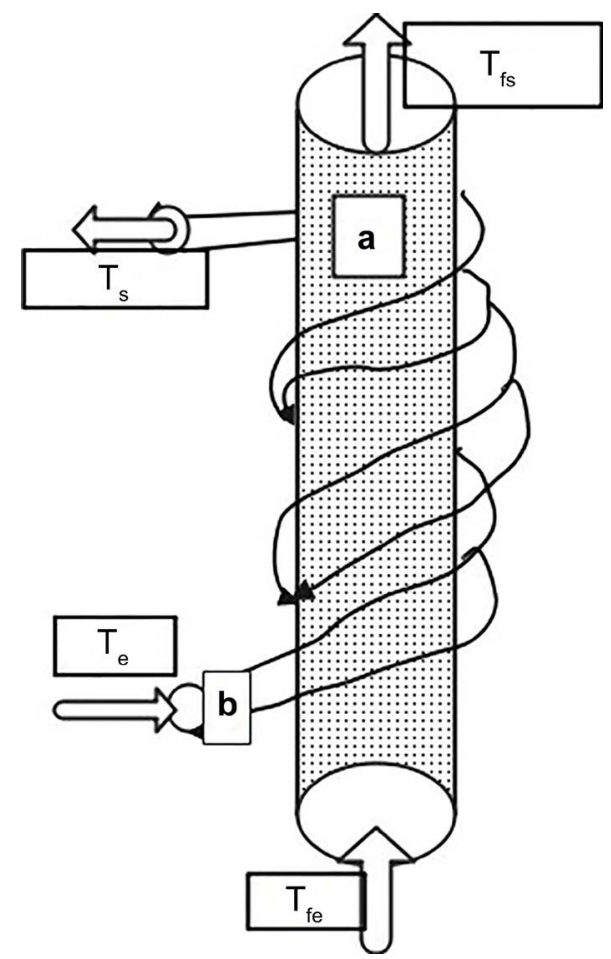

Figure 2. Physical model of the prototype.

- The flow of water is unidirectional and is vertical the radiation is negligible.

- The dominant mode of transfer along the walls of the tubes is conduction.

- The heat exchange between water and walls is essentially by convection.

- The mass heat of water is 4 times that of air $\left(C_{e}=4 C_{a}\right)$.

\subsection{Initial and Boundary Conditions}

- At the initial moment the water temperature $T_{a}=20^{\circ} \mathrm{C}$.

- The inlet temperature of the $T_{e f}$ fumes $=150^{\circ} \mathrm{C}$.

- The water outlet temperature is $T_{s}=90^{\circ} \mathrm{C}$.

- Water temperature at the entrance of the boiler $T_{e}=45.5^{\circ} \mathrm{C}$.

\subsection{The Recovery System Size}

The chimney has a maximum power of:

$$
P_{1 \max }=-D_{m} C_{p}\left(T_{s}-T_{e}\right)
$$

where is water mass flow $\mathrm{kg} / \mathrm{s}$, is mass heat of the water in $\mathrm{J} / \mathrm{kg} /{ }^{\circ} \mathrm{C}$.

$T_{e}-T_{s}$ is a difference in water inlet and outlet temperature in ${ }^{\circ} \mathrm{C}$.

It is necessary to assimilate the coil to a pipe of length $L$ and diameter $d$ is noted $\theta$ the temperature of the water in the coil when it has traveled the distance $x$ thereof from the inlet. The power balance on the elementary slice of the coil of elementary length $\mathrm{d} x$ can be made as represented by Figure 3 below. The incoming power through the section $x$ is:

$$
P=D_{m} C_{p} \theta
$$




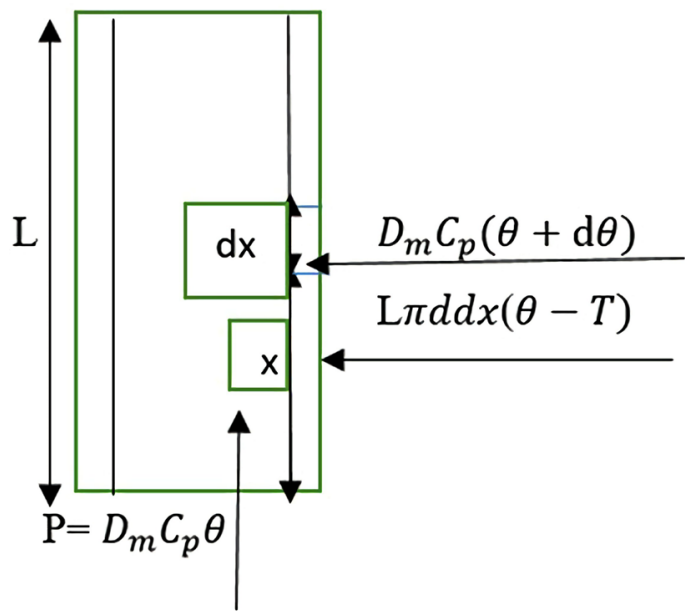

Figure 3. The model description.

where $P$ is the incoming power through section $x$ in (W); is water mass flow $\mathrm{kg} / \mathrm{s}$; is mass heat of the water in $\mathrm{J} / \mathrm{kg} /{ }^{\circ} \mathrm{C}$ and the temperature of the water at length $L=x$. The power transferred laterally to water by the chimney on a surface and temperature;

$$
P=L \pi d \mathrm{~d} x(\theta-T)
$$

where $P$ is the power ceded by the walls in (W); $L$ is the length of the tube in (m); the outer diameter of the tube in $(\mathrm{m}) d x$ the element variation of length in (m) and is the temperature difference between the temperature of the water at section $x$ and the temperature given by the boiler in $\left({ }^{\circ} \mathrm{C}\right)$. The outgoing power through the section $(x+\mathrm{d} x)$ where the water temperature is $\theta+\mathrm{d} \theta$.

$$
P=D_{m} C_{p}(\theta+\mathrm{d} \theta)
$$

where $P$ is the outgoing power through the section $\mathrm{d} x$ in $(\mathrm{W})$; is water mass flow $\mathrm{kg} / \mathrm{s}$; is mass heat of the water in $\mathrm{J} / \mathrm{kg} /{ }^{\circ} \mathrm{C}$ and the temperature of the water at length $L=x$. The conservation of powers gives Equation (5) below.

$$
\begin{gathered}
D_{m} C_{p} \theta=D_{m} C_{p}(\theta+\mathrm{d} \theta)+L \pi d \mathrm{~d} x(\theta-T) \\
D_{m} C_{p} \frac{\mathrm{d} \theta}{\mathrm{d} x}+L \pi d \theta=L \pi d T
\end{gathered}
$$

Therefore one obtains (6) a differential equation of the form.

$$
\frac{\mathrm{d} \theta}{\mathrm{d} x}+\frac{1}{\alpha} \theta=T
$$

with $\alpha=\frac{D_{m} C_{p}}{L \pi d} \quad x=0$ alors $\theta=T$ and $x=L$ where $\theta=T_{s}$.

With the use of boundary conditions gives Equation (7).

$$
T_{s}=\left(T_{e}-T\right) \mathrm{e}^{-\frac{L}{\alpha}}+T
$$

where $T_{e}$ is the temperature of the water at the entrance to the recovery system in $\left({ }^{\circ} \mathrm{C}\right) ; T$ is the temperature transmitted by the wall of the boiler chimney in 
$\left({ }^{\circ} \mathrm{C}\right), T_{s}$ is the outlet temperature of the water; $L$ is the length of the tube and is a constant.

\subsection{Heat Balance of the Recovery System}

The recovery system studied in this article has three temperature (Figure 4) levels among which the temperatures of entry and exit of cold water and the temperature ceded by the hot wall of the chimney. The temperature difference of the input and output is due to the heat transfer within the recovery system. By applying the volume control, the heat balance can be writing in Equation (9) below [13].

$$
V^{\prime} \varphi \cdot \frac{\mathrm{d} u}{\mathrm{~d} t}=\dot{m}_{s} \cdot h_{s}-\dot{m}_{e} \cdot h_{e}+p \frac{\mathrm{d} v}{\mathrm{~d} T}+A_{t} \cdot \dot{q}
$$

where $V^{\prime}$ is the control volume $\left(\mathrm{m}^{3}\right) ; \varphi$ is the density of water $\left(\mathrm{kg} / \mathrm{m}^{3}\right) ; u$ is internal mass-energy of water $(\mathrm{d} / \mathrm{kg}) ; t$ is the time $(\mathrm{s}) ; \dot{m}$ is water mass flow rate $(\mathrm{kg} / \mathrm{s}) ; p$ is water pressure $(\mathrm{Pa}) ; h$ is enthalpy by mass of water $(\mathrm{kg} / \mathrm{s}) ; A$ is exchange surface of the wall where the heat flow density $q$ is exchanged $\left(\mathrm{m}^{3}\right) ; \dot{q}$ is the power flow through the wall $\left(\mathrm{w} / \mathrm{m}^{3}\right)$. Assuming that the water is incompressible and that the model is in an established regime the terms that depend on time are therefore zero. Equations (10) and (11) below are formed;

$$
\begin{gathered}
\dot{m}_{s} \cdot h_{s}-\dot{m}_{e} \cdot h_{e}+A_{t} \cdot \dot{q}=0 \\
-\dot{m}_{s} \cdot h_{s}+\dot{m}_{e} \cdot h_{e}=A_{t} \cdot \dot{q}
\end{gathered}
$$

In addition, the mass enthalpy can be expressed to a constant for the product of its capacity by its temperature;

$$
h_{g}=C_{p e} T_{e}+h_{0}
$$

where $T_{e}$ is the temperature of the water $\left({ }^{\circ} \mathrm{C}\right)$; and $C_{p e}$ is the heat capacity of the water $\left(\mathrm{j} / \mathrm{kg} /{ }^{\circ} \mathrm{C}\right)$ by introducing (11) in (12) we obtain Equation (13) in the form;

$$
A_{t} \dot{q}=m_{e} C_{p e}\left(T_{e}-h_{0}\right)-m_{s} C_{p s}\left(T_{s}+h_{0}\right)
$$

The mass flow and heat capacity of the water remains constant throughout the absorber. (12) Will be written in the form of Equation (14) below;

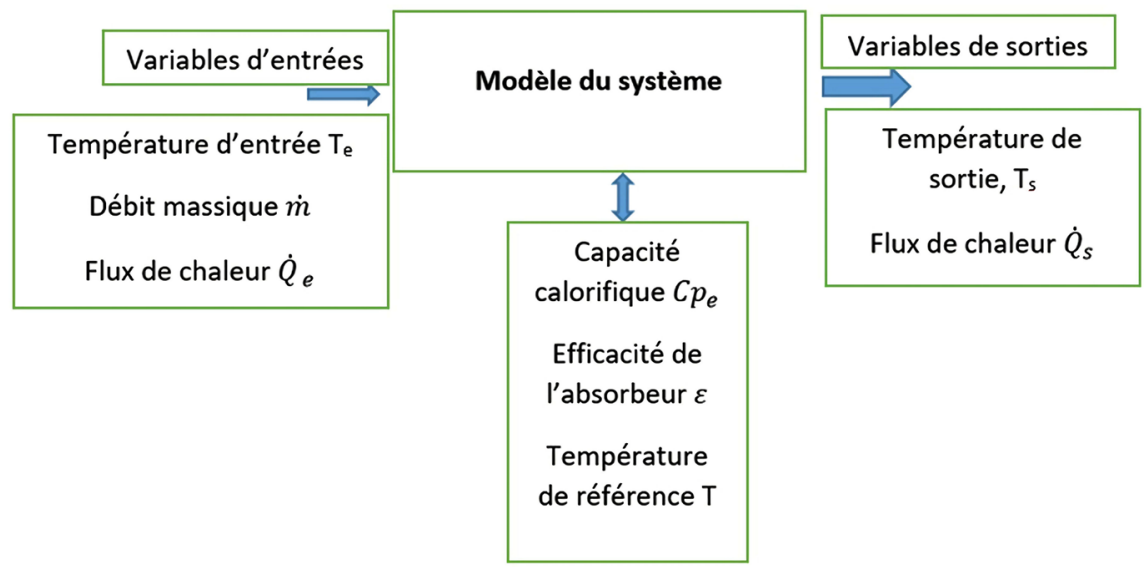

Figure 4. System model diagram. 


$$
A_{t} \dot{q}=m_{e} C_{p e}\left(T_{s}-T_{e}\right)
$$

The temperature profile of the water is known throughout the recovery system can be described write (12) as follows;

$$
\dot{Q}=A_{t} \dot{q}=\dot{m}_{e} C_{p e}\left(T_{s}-T_{e}\right)
$$

Therefore

$$
Q=m_{e} C_{p e} \Delta T_{e}
$$

where $T_{s}$ and $T_{e}$ the temperatures at the inlet and outlet of the exchanger respectively $\left({ }^{\circ} \mathrm{C}\right)$ and $\dot{Q}$ is thermal power exchanged in (w). To characterize the performance of the recovery system, efficiency can be an appropriate parameter defined as the ratio of the thermal power exchanged to the maximum power theoretically possible with the same condition of water inputs into the exchanger;

$$
\varepsilon=\frac{\dot{Q}_{\text {rélle }}}{\dot{Q}_{\max }}=\frac{\dot{m}_{e} C_{p e}\left(T_{e}-T_{s}\right)}{\dot{Q}_{\max }}
$$

By introducing (5) in (15) we obtain (16) below

$$
\varepsilon=\frac{T_{e}-\left(T_{e}-T\right) \mathrm{e}^{-\frac{L}{\alpha}}-T}{T-T_{e}}
$$

\section{Results and Discussion}

We consider the inlet temperature $T_{e}$ of cold water at the ambient temperature of $45.5^{\circ} \mathrm{C}$. Figure 5 below shows the temperature of the chimney that decreases by $112^{\circ} \mathrm{C}$ when the length of the tube increases from 110 to $120 \mathrm{~m}$. This confirms the existing correlation between the temperatures transmitted to the water considered less important when the length of the tube increases. It should be noted that the decrease of the temperature also means that the recovery system studied in this work effectively absorbs heat.

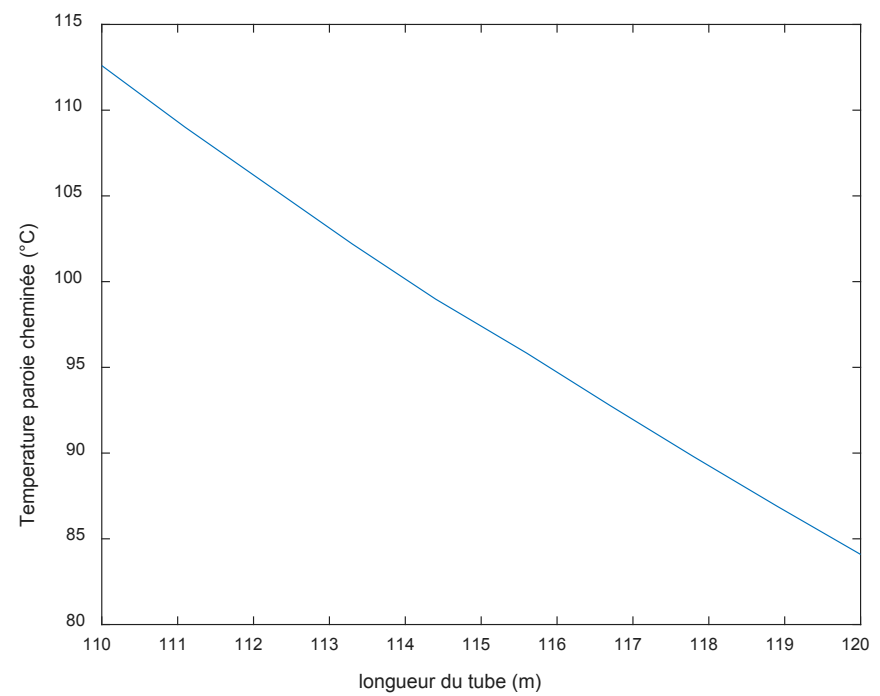

Figure 5. Stack wall temperatures as a function of tube length. 
Figure 6 indicates the fact that water temperature on the outlet of the recovery system is a function of the length of the tube. It is observed a variation in the water temperature from $89^{\circ} \mathrm{C}$ to $98.9^{\circ} \mathrm{C}$ when the same length of the tube (Figure 4) is used. This result confirms the results of [2] in 2013 which had found a temperature of the hot spring of $70^{\circ} \mathrm{C}$ and a COP value between 0.35 and 0.46 . The results after simulation carried out by [3] obtained the temperature of $60^{\circ} \mathrm{C}$ as a hot source allows also to validate this research.

Figure 7 shows the variations in the temperature of the water outlet relative to the temperature of the wall of the chimney. It appears that the temperature of the water on the outlet of the recovery system increase with the length of the tube. This water outlet temperature varies between $85.7^{\circ} \mathrm{C}$ and $95.6^{\circ} \mathrm{C}$ which allows having a significant preheating temperature. This temperature allows to save the fuel consumption and control the energy consumption that led to set the outlet temperature at $90^{\circ} \mathrm{C}$. This outlet temperature can be validated as an average temperature.

Figure 8 shows the variations in the energy efficiency of the recovery system studied as a function of the length of the tube. The result of the graph shows that the efficiency of this recovery system increases with the length of the tube. This increase in energy efficiency is logical because Figure 5 demonstrated that the temperature of outlet water increased with the tube which allowed to have an energy efficiency between 0.55 and 0.57 . The portion of tube length chosen (110; 111) $\mathrm{m}$, this result improves the efficiencies of [2] who has also worked in the permanent regime and [12] although it does not work in steady state, it still evaluates the performance of a recuperator and especially with working fluid that should impact on the energy efficiency, whose efficiencies are respectively 0.35 to $0.46 \%$ and $4.93 \%$. This result allows confirming the model energy efficiency developed when compared with the result of [2].

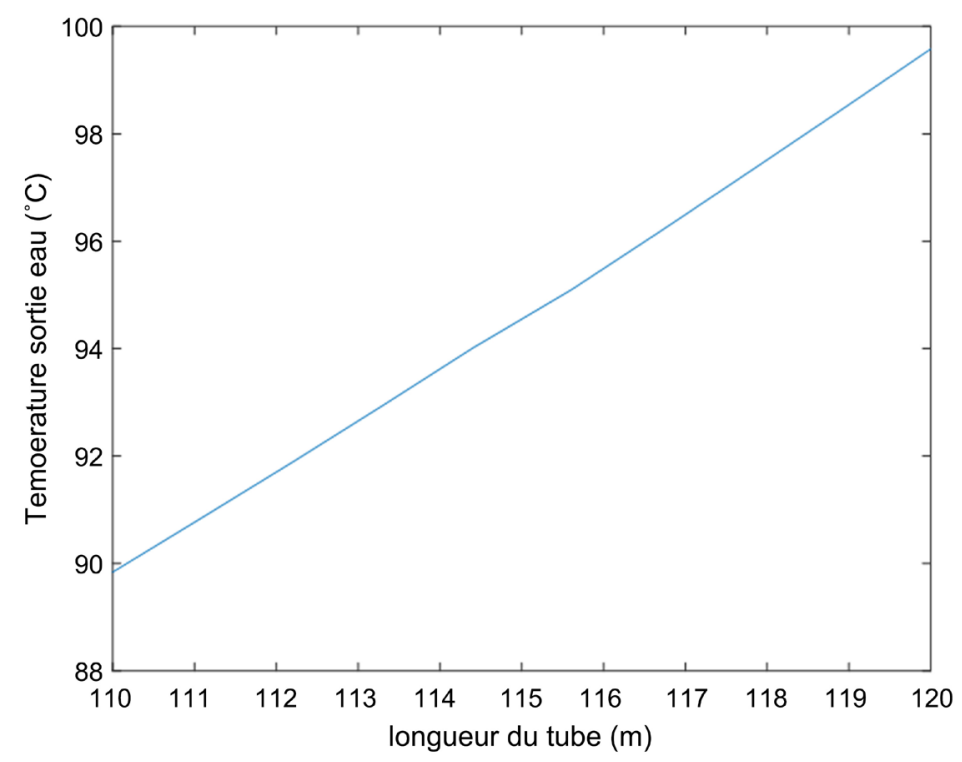

Figure 6. Recovery outlet water temperature as a function of tube length. 


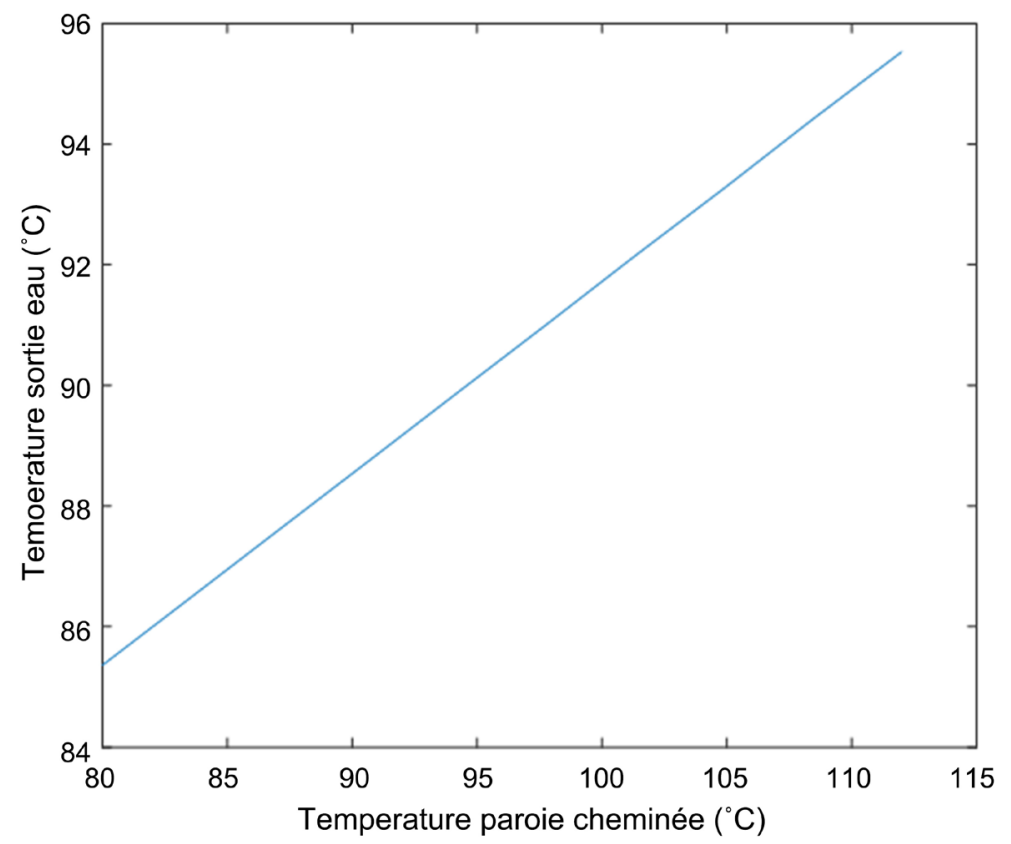

Figure 7. Recovery outlet water temperature as a function of chimney wall temperature.

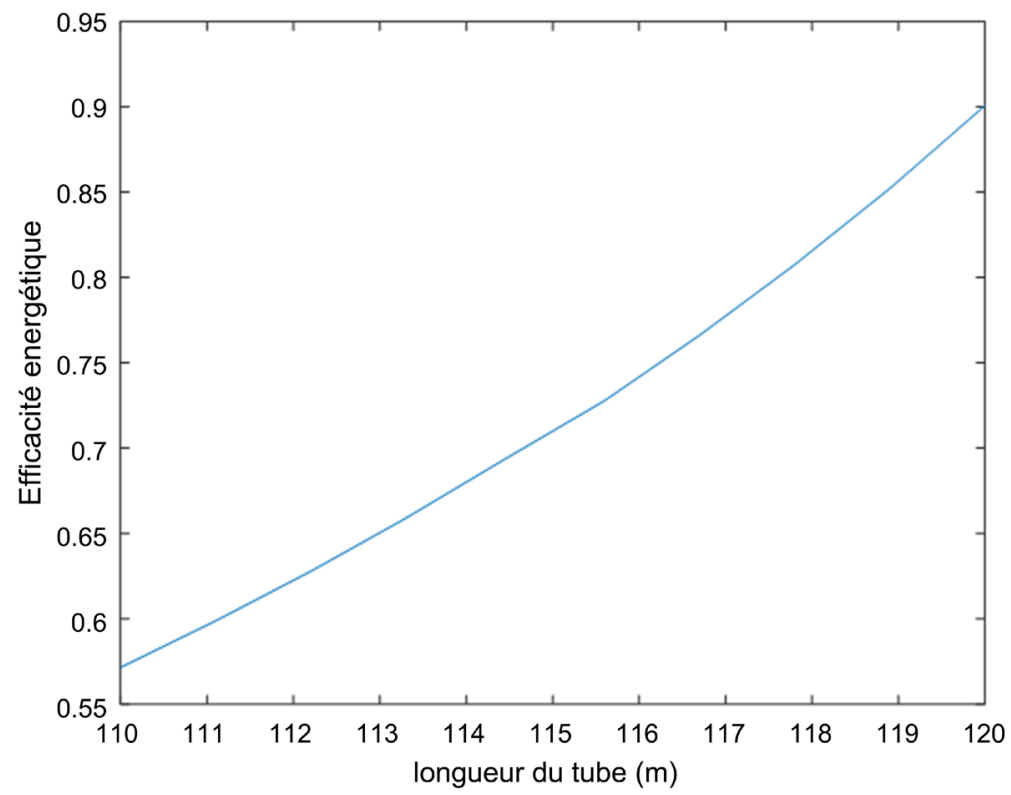

Figure 8. Recovery energy efficiency as a function of tube length.

\section{Conclusions}

Steady-state working fluid modeling is a type of modeling that allows you to evaluate the performance of a system with external parameters provided. The modeling of heat transfer uses thermodynamic principles to evaluate the thermodynamic balance of the recovery system of condensing boiler. The heat exchange in the recovery system of condensing boiler.

The results of this study showed that the recovery unit can absorb temperatures ranging from $88^{\circ} \mathrm{C}$ to $90.7^{\circ} \mathrm{C}$ when the length of the tube is between $110 \mathrm{~m}$ 
and $111 \mathrm{~m}$. The results also confirm that the energy efficiency is between 0.55 and 0.57 . These results allowed to validate the model when compared to the literature. One of the advantages is the fast its ease of use with an almost instantaneous calculation time. It is also less cumbersome and may require financial means for its realization it is well recommended for some countries such as Cameroon.

\section{Conflicts of Interest}

The authors declare no conflicts of interest regarding the publication of this paper.

\section{References}

[1] Mbiake, R. (2018) Renewable Energies in the Political Field and Equals Energy in Cameroon. Nomos, URL.

https://www.jstor.org/stable/j.ctv941sr6.36?seq=1\#metadata_info_tab_contents

[2] Arivazhagan, S., Murugesan, S.N., Saravanan, R. and Renganarayanan, S. (2005) Simulation Studies on R134a-DMAC Based Half Effect Absorption Cold Storage Systems. Energy Conversion and Management, 46, 1703-1713.

https://doi.org/10.1016/j.enconman.2004.10.006

[3] Zhang, C.H., Zhao, Y.B., Shi, X.M. and Huang, X.P. (2020) Characterization of a New Total Heat Recovery System Using $\mathrm{CaCl} 2$ as Working Fluid: Thermal Modeling and Physical Analysis. Energy and Built Environment, 12. https://doi.org/10.1016/j.enbenv.2020.12.003

[4] Zhen, H.R., Feng, W.L. and Wang, S. (2020) Analysis of Application Effect of Hot Water Storage Technology in Flue Gas Waste Heat Recovery. Journal of District Heating, 153-158.

[5] Pashchenko, D. (2019) Thermochemical Recovery by Ethanol Steam Reforming: Thermodynamic Analysis and Heat Balance. International Journal of Hydrogen Energy, 44, 30865-30875. https://doi.org/10.1016/j.ijhydene.2019.10.009

[6] Zhang, H.Z., Han, Z.W., Yang, L.Y., Yuan, J.W., Cheng, X.L., Ji, M.Z. and Li, G. (2020) Analysis of Influence of the Length of Ground Heat Exchangers on the Operation Characteristics and Economy of Ground Source Heat Pumps. Energy and Built Environment, 2, 127-136. https://doi.org/10.1016/j.enbenv.2020.09.003

[7] Yue, L., Wu, J., Cao, F., Xue, R., Ma, H., and Yang, J. (2020) Design of a New Gas Waste Heat Recovery Device. Journal of Science and Technology Innovation, 33, 189-190.

[8] Amaris, C., Miranda, B.C. and Balbis, M. (2020) Experimental Thermal Performance and Modelling of a Waste Heat Recovery Unit in an Energy Cogeneration System. Thermal Science and Engineering Process, 20, Article No. 100684. https://doi.org/10.1016/j.tsep.2020.100684

[9] Fu, L., Tian, G.S., Sui, J. and Jiang, Y. (2003) Application of Absorption Heat Pump in Gas Heating and Condensing Heat Recovery. Acta Energiae Solaris Sinica, 24, 620-624.

[10] Liu, J., Ye, B.C. and Chen, G.M. (2015) Study on the Performance of Open Cycleabsorption Heat Recovery System for Waste Heat Recovery. Journal of Engineering Thermophysics, 36, 474-477. 
[11] Wang, F. and Wang, Q. (2020) Deep Recovery Technology of Waste Heat from Boiler Flue Gas in Cold Region. Journal of Science and Technology Innovation, 34, 193-194.

[12] Thaddaeus, J., Tanimu, I., Okon, E. and Ikeokwu, E. (2021) Innocent Performance Assessment of a Heat Recovery Unitusing a Turbine with Variableguide Vane Configuration for Application in Passenger Vehicles. Journal of Power and Energy Engineering, 9.

[13] Wang, Y.X. (2017) Stratégie de modélisation des systèmes de valorisation énergétique: Applicationaux machines ORC et à absorption. Thèse, Université de Lyon, Lyon, 79 p. 